\title{
Pengembangan UKM dan Penguatan Kelembagaan BUMDes di Desa Kikia Kecamatan Sumalata Kabupaten Gorontalo Utara
}

\author{
Fenti Prihatini Tui ${ }^{1}$, Rustam Tohopi ${ }^{2}$, Irawaty Igirisa ${ }^{3}$, Mitravin Igirisa ${ }^{4}$, \\ Frengky Reymond Jantu ${ }^{5}$ \\ $1,2,3$ Universitas Negeri Gorontalo, Jl. Jend. Sudirman No. 6 Dulalowo Timur, Kota \\ Tengah, Kota Gorontalo, Indonesia \\ 4,5 Pemda Gorontalo Utara, Indonesia \\ fenti@ung.ac.id ${ }^{1 *}$, rustam@ung.ac.id ${ }^{2}$, irawatyigirisa17@ung.ac.id ${ }^{3}$, \\ idabundamitra@gmail.com ${ }^{4}$, reymondfxinsp@gmail.com ${ }^{5}$
}

\begin{abstract}
Abstrak
Kajian ini bertujuan untuk membahas upaya pengembangan UKM dan penguatan kelembagaan BUMDes di Desa Kikia Kecamatan Sumalata Kabupaten Gorontalo Utara. Fenomena yang terjadi pada UKM dan BUMDes yang belum mampu mengembangkan usahanya menjadikan kegiatan ini sangat perlu untuk dilakukan. Disamping itu, kegiatan ini dilaksanakan bersama mahasiswa KKN yang ditugaskan di Desa Kikia dan ditunjang dengan kegiatan pemerintah desa. Kegiatan pemberdayaan masyarakat ini melibatkan dinas terkait dari Kabupaten Gorontalo Utara, UKM yang sukses dan pakar dari Universitas Negeri Gorontalo. Model pemberdayaan yang dilakukan melalui pembinaan, diklat dan pendampingan kepada UKM dan pengurus BUMDes di Desa Kikia. Kegiatan telah dilaksanakan selama dua bulan dengan melibatkan 30 orang mahasiswa yang ditempatkan di Desa Kikia dan diharapkan dapat meningkatkan pendapatan masyarakat dan menguatkan kelembagaan BUMDes. Setelah dilakukan kegiatan pemberdayaan maka hasil yang dicapai adalah dua UKM mampu mengembangkan kemampuannya dalam membuat acar ikan dan kripik pisang tanduk serta kelembagaan BUMDes yang tertata baik dari aspek administrasi keuangan maupun manajemen usahanya. Target akhir dari kegiatan pemberdayaan ini adalah dihasilkannya artikel ilmiah yang diterbitkan dalam jurnal yang terindeks, sehingga model pemberdayaan masyarakat yang diterapkan di Desa Kikia dapat dijadikan rekomendasi untuk menyelesaikan permasalahan yang sama yang dihadapi oleh masyarakat ditempat lain.
\end{abstract}

Kata Kunci: pemberdayaan, penguatan kelembagaan, UKM, BUMDes

\begin{abstract}
This study aims to discuss efforts to develop UKM and strengthen BUMDes institutions in Kikia Village, Sumalata District, North Gorontalo District. The phenomenon that occurs in UKM and BUMDes that have not been able to develop their business makes this activity very necessary to do. In addition, this activity is carried out with KKN students assigned to Kikia Village and supported by village government activities. This community empowerment activity involves relevant agencies from North Gorontalo District, successful UKM and experts from Gorontalo State University. The empowerment model is carried out through coaching, training and mentoring for UKM and BUMDes administrators in Kikia Village. The activity has been carried out for two months involving 30 students who are stationed in Kikia Village and are expected to increase community income and strengthen BUMDes institutions. After the empowerment activities were carried out, the results achieved
\end{abstract}


were that two SMEs were able to develop their abilities in making fish pickles and horn banana chips as well as BUMDes institutions that were well organized in terms of financial administration and business management. The final target of this empowerment activity is the production of scientific articles published in indexed journals, so that the community empowerment model applied in Kikia Village can be used as a recommendation to solve the same problems faced by people in other places.

Keywords: empowerment, institutional strengthening, UKM, BUMDes

(C) 2020 Fenti Prihatini Tui, Rustam Tohopi, Irawaty Igirisa, Mitravin Igirisa, Frengky Reymond Jantu Under the license CC BY-SA 4.0

Correspondence author: Fenti Prihatini Tui, fenti@ung.ac.id, Gorontalo, and Indonesia

\section{PENDAHULUAN}

Salah satu misi pemerintah Indonesia dalam membangun pedesaan adalah untuk memberdayakan masyarakat dan pada akhirnya akan meningkatkan produktivitas dan keragaman bisnis di pedesaan. (Sofyani, H., Atmaja, R., \& Rezki, S. B, 2019) Untuk mencapai tujuan tersebut, maka program pembangunan yang dilaksanakan oleh pemerintah saat ini harus mencakup semua aspek dan sendi perekonomian masyarakat. Program pembangunan dilaksanakan untuk meningkatkan pendapatan masyarakat (Igirisa, I., Rahman, M., Abdussamad, J., Abdusamad, Z., \& Husain, A. K, 2020). Usaha Kecil dan Menengah (UKM) sebagai salah satu ujung tombak dan pelaku usaha yang berakar dari usaha kecil yang dilakukan oleh masyarakat diseluruh pelosok desa turut memainkan peranan dalam menghidupkan perekonomian masyarakat.

UKM memiliki peran penting dalam menggerakkan perekonomian Indonesia (Hadi Purnomo, S, 2018). Di Desa Kikia Kecamatan Sumalata terdapat dua UKM yaitu UKM pengolahan hasil perikanan 
dan UKM pengolahan hasil pertanian. Kedua UKM ini bergabung dan dibina oleh lembaga BUMDes yang pengelolaannya dilakukan oleh masyarakat dan pemerintah Desa Kikia. Selama ini kegiatan UKM dan BUMDes belum terlalu efektif, karena adanya beberapa faktor seperti modal dan keterbatasan kemampuan dari pengelola. Pertumbuhan UKM dibatasi oleh ketersediaan keuangan internal (Moscalu, M., Girardone, C., \& Calabrese, R, 2020).

Realitas yang ditemukan di Desa Kikia, dimana pengelola UKM belum mampu mengembangkan usahanya walaupun potensi yang dimiliki oleh desa sangat banyak. Hasil penelitian sebelumnya menunjukkan bahwa perkembangan UKM dengan semangat meningkatkan kemandirian secara ekonomi telah memberikan dampak positif pada peguatan perekonomian lokal (Puspitaningtyas, Z, 2017). Fenomena yang terjadi pada BUMDes di Desa Kikia, pengelola belum mampu mengelola administrasi keuangan dan manajemen usahanya, walaupun pemerintah desa telah mengalokasikan dana ADD untuk menambah modal usaha yang digunakan dalam kegiatan operasional BUMDes. Pembangunan di tingkat desa masih memiliki banyak kelemahan, seperti halnya dengan kualitas sumber daya manusia dan manajemen organisasi (Razak, M. R. R., \& Sofyan, B, 2020). Oleh karena itu, kegiatan pemberdayaan pada masyarakat ini sangat tepat dilakukan di Desa Kikia, dengan sasaran utama lembaga BUMDes dan UKM. Keberadaan BUMDes sebagai lembaga yang menjadi wadah bagi pengembangan beberapa unit usaha yang dilaksanakan oleh masyarakat dan pemerintah desa masih perlu dibenahi. Selama ini pengelolaan BUMDes masih dilaksanakan secara konvensional dan belum menggunakan sistem pengelolaan keuangan yang mengacu 
pada pedoman pengelolaan akuntansi keuangan yang tepat. Manajemen usahanyapun belum mampu berkembang dengan baik karena keterbatasan kemampuan dari pengurus BUMDes. Hasil usaha dari BUMDes diaplikasikan untuk meningkatkan kesejahteraan masyarakat pedesaan (Utami, W., \& Nugroho, L, 2019). Disamping itu, potensi yang dimiliki oleh Desa Kikia yang berasal dari hasil perikanan dan pertanian belum dikelola dengan baik oleh masyarakat maupun UKM, sehingga belum berdampak pada peningkatan pendapatan masyarakat.

Permasalahan diselesaikan melalui kegiatan pemberdayaan pada masyarakat yang dilakukan dengan memberikan diklat dan pendampingan dengan melibatkan mahasiswa di Desa Kikia. Kegiatan pemberdayaan ini diharapkan dapat membantu masyarakat dalam meningkatkan pendapatan, menguatkan kelembagaan BUMDes sehingga diharapkan BUMDes Desa Kikia akan menjadi percontohan untuk BUMDes lainnya di Gorontalo Utara dan di daerah lainnya. BUMDes juga merupakan alat pemberdayaan ekonomi lokal dengan berbagai jenis potensi yang ada di desa, harus menjadi tulang punggung ekonomi pemerintah desa dalam mencapai peningkatan kesejahteraan warganya (Ramly, A., Wahyuddin, W., Jullimursyida, J., \& Mawardati, M, 2020). Keseluruhan kegiatan pemberdayaan pada masyarakat ini akan di jadikan sebagai artikel ilmiah yang akan dipublikasikan pada jurnal bereputasi sehingga diharapkan dapat menjadi referensi dan dijadikan sebagai rekomendasi untuk menyelesaikan permasalahan yang sama di daerah lainnya. 


\section{METODE PELAKSANAAN}

Kegiatan ini dilaksanakan dengan menggunakan model pemberdayaan pada masyarakat. Pemberdayaan adalah strategi penting yang digunakan banyak organisasi untuk meningkatkan kekuatan (Hanaysha, J, 2016). Kegiatan dilakukan melalui metode ceramah, diklat dan pendampingan kepada UKM dan Pengelola BUMDes di Desa Kikia. Sasaran kegiatan adalah pengelola UKM yaitu UKM pengolahan hasil perikanan dan UKM pembuatan kripik pisang, serta pengurus BUMDes dengan melibatkan aparat pemerintah desa. Kegiatan dilakukan selama dua bulan dengan didampingi oleh mahasiswa peserta KKN yang ditempatkan di Desa Kikia.

Untuk melaksanakan kegiatan pelatihan bagi UKM diundang pemateri dari UKM yang sukses dan tim dari Universitas Negeri Gorontalo. Sedangkan untuk penguatan kelembagaan BUMDes melibatkan dinas terkait dari Kabupaten Gorontalo Utara yang didampingi oleh tim dari Fakultas Ekonomi Universitas Negeri Gorontalo. Semua tahapan kegiatan pemberdayaan kepada UKM dan BUMDes di adakan evaluasi pada saat kegiatan, setelah itu dilakukan pendampingan dan evaluasi pada tahap akhir.

Hasil akhir yang diharapkan dari kegiatan ini adalah kedua UKM akan mampu mengembangkan usaha pembuatan acar ikan dan kripik pisang, sehingga mampu menghasilkan produk yang siap dipasarkan di Gorontalo Utara sampai ke daerah lainnya. Disamping itu kelembagaan BUMDes akan tertata dengan baik ditinjau dari aspek administrasi keuangan maupun manajemen usahanya, sehingga BUMDes di Desa Kikia bisa dijadikan sebagai BUMDes percontohan diwilayah Gorontalo Utara. Tingkat penguasaan materi dan perubahan yang terjadi pada 
UKM dan kelembagaan BUMDes akan menunjukkan keberhasilan dari kegiatan pemberdayaan pada masyarakat yang dilakukan di Desa Kikia Kecamatan Sumalata Kabupaten Gorontalo Utara.

\section{HASIL DAN PEMBAHASAN}

\section{Hasil}

Upaya peningkatan pendapatan masyarakat dapat dilakukan melalui kegiatan pemberdayaan pada masyarakat yang bertujuan untuk menguatkan kelembagaan UKM dan BUMDes. Keberadaan lembaga keuangan di desa ditujukan untuk meningkatkan kemudahan akses keuangan masyarakat desa (Feriady, M, Kusmuriyanto, 2019). Beberapa permasalahan yang terjadi di Desa Kikia dapat diselesaikan melalui diklat dan pendampingan kepada UKM dan BUMDes.

Secara singkat hasil kegiatan pemberdayaan pada masyarakat di Desa Kikia Kecamatan Sumalata dapat dideskripsikan sebagai berikut:

1. Penataan administrasi dan manajemen usaha Penataan administrasi dan manajemen usaha UKM dan BUMDes merupakan salah satu aspek yang menentukan dalam penguatan kelembagaan perekonomian masyarakat desa. Berbagai usaha kecil yang digerakkan oleh kelompok masyarakat baik itu UKM maupun BUMDes sangat memerlukan penataan administrasi dan manajemen usaha.

2. Penguatan kelembagaan UKM dan BUMDes

Kelembagaan BUMDes merupakan aspek yang harus diperhatikan. Maju mundurnya usaha yang dijalankan oleh BUMDes turut ditentukan oleh aspek kelembagaan dan manajemen usaha. Untuk itu pengelola BUMDes harus diberikan pelatihan tentang 
pengelolaan manajemen usaha dan pengelolaan administrasi keuangan.

3. Pengembangan UKM pengolahan hasil perikanan

Potensi hasil perikanan yang ada di Desa Kikia cukup banyak dan perlu dikembangkan guna menopang perekonomian masyarakat. Untuk itu dilakukan pelatihan pengolahan hasil perikanan seperti pembuatan acar ikan. Kegiatan dilakukan dengan melibatkan UKM pengolahan hasil perikanan dan masyarakat yang ada di Desa Kikia.

4. Pengembangan UKM pengolahan hasil pertanian

Bidang pertanian dan perkebunan menjadi sumber mata pencaharian dari masyarakat di Desa Kikia. Salah satu hasil kebun yang banyak ditemukan adalah pisang. Potensi ini bisa dikembangkan oleh UKM pengolahan hasil pertanian, sehingga tim mengadakan pelatihan pembuatan Kripik Pisang Tanduk.

\section{Pembahasan}

Pengembangan potensi di Desa Kikia dilakukan melalui kegiatan pemberdayaan masyarakat yang terhimpun dalam UKM dan BUMDes. Kebijakan tentang pendirian BUMDes merupakan salah satu bukti bahwa pemerintah diharapkan untuk mampu berbisnis. (Kurniasih, D., \& Setyoko, P.I., Wijaya, S.S, (2019).

Dari hasil kegiatan yang telah dilaksanakan oleh tim bersama mahasiswa peserta KKN yang ditempatkan di Desa Kikia, diharapkan pendapatan masyarakat akan meningkat. Kegiatan yang telah dilaksanakan dibahas melalui uraian berikut:

1. Penataan administrasi dan manajemen usaha

Suatu organisasi dapat berjalan lancar bila ditunjang dengan sistem administrasi dan manajemen usaha yang dikelola dengan baik. 
Oleh karena itu, aspek sumber daya manusia yang memiliki kompetensi dan pengalaman dalam mengembangkan organisasi sangat diperlukan. Sumber daya manusia yang dihasilkan dan aktif memiliki peran strategis dalam organisasi. De la Lastra, S. F.-P., Martin-Alcazar, F., \& Sanchez-Gardey, G. (2014).

Realitas yang ditemukan, upaya pengembangan UKM dan BUMDes masih kurang dilakukan. Riset sebelumnya menunjukkan bahwa masih adanya kekurangan keterampilan manajemen dan pelatihan yang diberikan dalam sektor UKM (Jones, P., Beynon, M. J., Pickernell, D., \& Packham, G, 2013). Oleh karena itu, kegiatan pemberdayaan masyarakat yang dilakukan melalui penataan administrasi dan manajemen usaha UKM dan BUMDes yang ada di Desa Kikia telah dilakukan melalui metode ceramah dan diklat. Pengelola UKM dan BUMDes telah diberikan pelatihan pengelolaan administrasi dan manajemen usaha dengan melibatkan pemateri dari Fakultas Ekonomi Universitas Negeri Gorontalo. Selanjutnya diadakan pendampingan oleh mahasiswa peserta KKN yang ada di Desa Kikia dan pemantauan oleh Dosen Pembimbing Lapangan. Dari kegiatan yang telah dilaksanakan diharapkan administrasi dan manajemen usaha dari UKM dan BUMDes yang ada di Desa Kikia akan tertata dengan baik. Dampak akhir dari kegiatan ini adalah peningkatan pendapatan UKM dan masyarakat. Pendapatan UKM merupakan salah satu sumber pendapatan rumah tangga yang secara tidak langsung memberikan kontribusi terhadap pendapatan rumah tangga atau masyarakat (Rekarti, E., \& Doktoralina, C. M, 2017). Kegiatan pelatihan penataan administrasi dan manajemen usaha UKM dan BUMDes dapat dilihat melalui gambar berikut: 


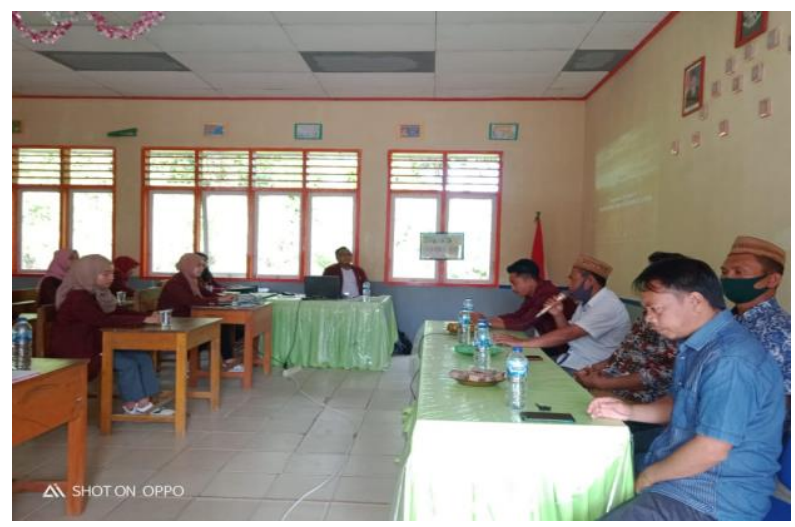

Gambar 1. Kegiatan pelatihan penataan administrasi dan manajemen usaha UKM dan BUMDes di Desa Kikia Kecamatan Sumalata

\section{Penguatan kelembagaan UKM dan BUMDes}

BUMDes adalah sebuah lembaga yang dapat digunakan untuk mengembangkan semua potensi yang dimiliki oleh masyarakat. Seperti halnya potensi dibidang perikanan dan pertanian yang ada di Desa Kikia perlu dikembangkan melalui BUMDes. Realitas yang ditemukan, ternyata BUMDes di Desa Kikia dilihat dari aspek kelembagaannya belum sesuai dengan tuntutan peran yang diharapkan oleh masyarakat. Oleh karena itu, melalui kegiatan pemberdayaan ini tim telah melakukan kegiatan penguatan kelembagaan BUMDes. Upaya peningkatan peran aktif kelompok merupakan salah satu bentuk penguatan kelembagaan (Igirisa, I., Isa, R. A., \& Tohopi, R, 2020). Diklat dilakukan dengan mengundang pemateri dari Pemda Kabupaten Gorontalo Utara terutama dalam pengelolaan kelembagaan dan keuangan BUMDes. Mahasiswa yang ditempatkan dilokasi pengabdian dilibatkan dalam kegiatan pendampingan terhadap penguatan kelembagaan BUMDes di Desa Kikia. Untuk jelasnya kegiatan pelatihan dapat dilihat melalui gambar berikut: 

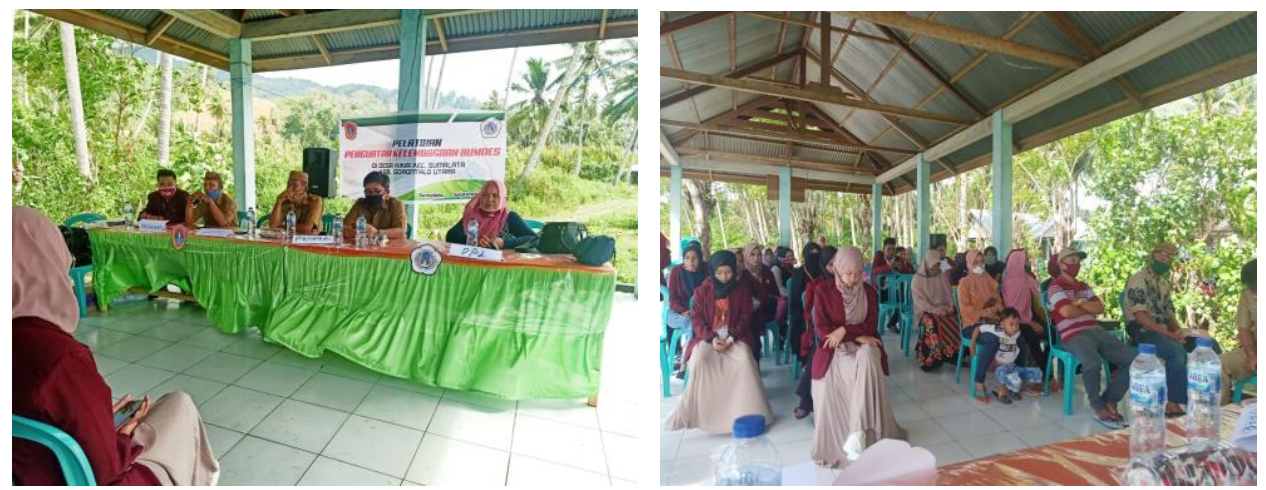

Gambar 2. Kegiatan pelatihan Penguatan Kelembagaan UKM dan BUMDes di Desa Kikia Kecamatan Sumalata

3. Pengembangan UKM pengolahan hasil perikanan

Wilayah Desa Kikia yang berada di pinggiran pantai memberikan peluang kepada masyarakat untuk mengembangkan potensi hasil perikanan. Perkembangan kegiatan pengolahan dan budidaya pesisir yang diintegrasikan dengan penangkapan ikan dapat meningkatkan pendapatan dan efisiensi bisnis. Masyarakat yang sebagian besar berprofesi sebagai nelayan memiliki kesempatan untuk mengembangkan UKM yang dapat mengolah hasil perikanan. Oleh karena itu, diadakan pelatihan pengolahan hasil perikanan berupa pembuatan acar ikan. Potensi ikan tuna, cakalang dan jenis ikan lainnya dapat digunakan untuk meningkatkan pendapatan masyarakat. Upaya diversifikasi hasil olahan ikan dapat dilakukan oleh UKM pengolahan ikan yang akan di Desa Kikia.

Dalam kegiatan pemberdayaan ini, telah dilakukan pelatihan pembuatan acar ikan dengan mengundang pemateri dari salah satu UKM yang sukses di Gorontalo Utara. Masyarakat dan pengelola UKM Pengolahan hasil perikanan diberikan pelatihan dan didampingi oleh mahasiswa yang ditempatkan di Desa Kikia. Untuk memaksimalkan 
hasil pelatihan, maka UKM di dorong untuk memproduksi acar ikan agar dapat dipasarkan kewilayah Kwandang atau ke Kota Gorontalo. Untuk itu, tim telah merancang desain kemasan acar ikan sehingga diharapkan UKM dapat segera menjual hasil produksinya dan dapat meningkatkan pendapatan yang diterima oleh masyarakat dan UKM tersebut. Kegiatan pemberdayaan dapat dilihat melalui gambar berikut:
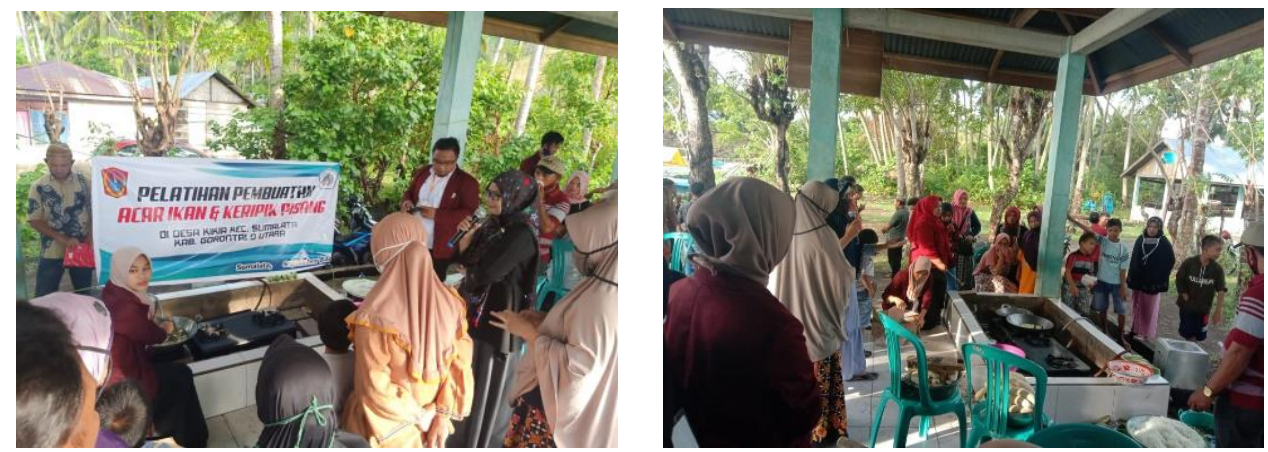

Gambar 3. Kegiatan pelatihan Pengembangan UKM pengolahan hasil perikanan

4. Pengembangan UKM pengolahan hasil pertanian

Setiap desa memiliki potensi dibidang pertanian dan perkebunan yang mendukung sektor-sektor lainnya. Karena untuk desa di Kecamatan Sumalata rata-rata memiliki komoditas hasil pertanian dan perkebunan. Di desa Kikia komoditas hasil pertanian dan perkebuanan sangat unggul dan prospektif beberapa tanaman diantaranya jagung, pisang, cabe, sayur-sayuran, dan lain-lain, sehingga pada masa yang akan datang kondisi tersebut dapat dikembangkan dan hal tersebut dapat mendukung ekonomi desa disektor pertanian. Komoditas pertanian ini jika dikelolad an dikembangkan dengan baik oleh peerintah desa Kikia misalanya melalui diversifikasi produk olahan hasil pertanian dan perkebunan akan meningkatkan ekonomi sudatu daerah khususny di di desa Kikia kecamatan Sumalata Kabuapaten Gorontalo 
Utara. Jenssen yang dikuatkan oleh pendapat Supranto dan Limakrisna (2011) dalam Kartikawati (2015) yang menyatakan bahwa beberapa hal yang harus diperhatikan dalam aktivitas ekonomi suatu daerah diantaranya meliputi: 1) potensi ekonomi apa yang dimiliki daerah yang bersangkutan; 2) prioritas pengembangan ekonomi dari potensi daerahnya tersebut; 3) setelah mampu mengenali potensi dan prioritas apakah mereka mampu menjual dan memasarkan prioritas daerahnya; 4) setelah mampu memasarkan, apakah ada investor datang dan mampu mengelolanya.

Hasil survey Tim KKN Tematik UNG bahwa saat panen pisang, masyarakat hanya untuk konsumsi rumah tangga. Setiap hasil penen hanya cukup dibagikan kepada masyarakat lain yang membutuhkan, bahkan jika hasil paen pisang melimpah banyak pisang yang membusuk ditempat saja. Masyarakat belum memasarkannya ke desa tetangga maupun kepasar mingguan di wilayah lain. Permasahan inilah oleh tim bekerjasama dengan pemerintah desa Kikia melakukan pelatihan pembuatan Keripik Pisang Tanduk dengan dikemas dan desain produk baru yakni keripik pisang susu yang dibumbui keju (pisuke) yang menghadirkan pengelola UKM di wilayah Kabupaten Gorontalo Utara. Melalui kegiatan ini harapannya hasil perkebunan khususnya pisang tanduk dapat diolah menjadi keripik pisang dan dapat dipasarkan sebagai konsumsi masyarakat diluar desa Kikia itu sendiri. Kegiatan pemberdayaan dapat dilihat melalui gambar berikut: 

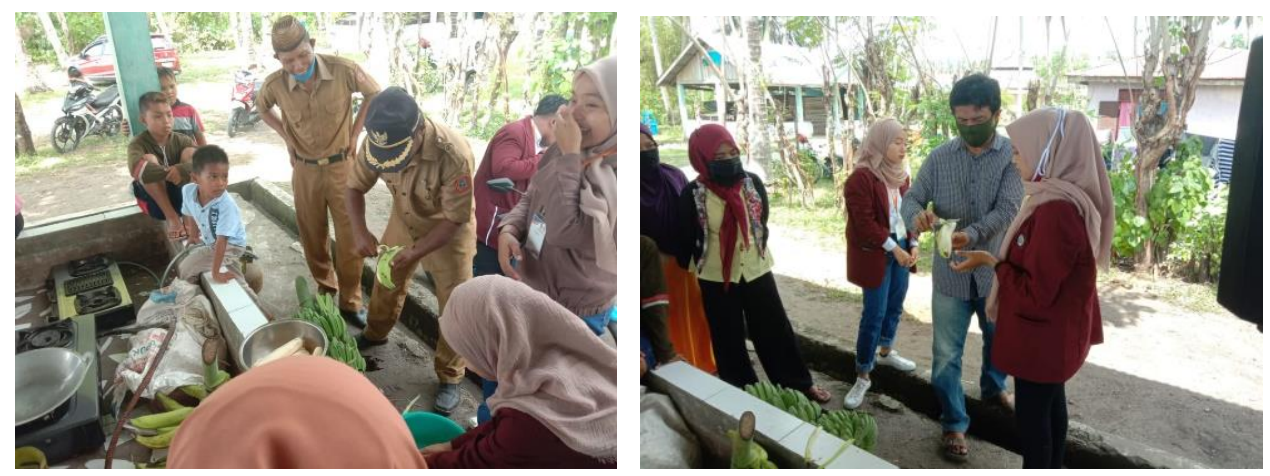

Gambar 4. Kegiatan pelatihan Pengembangan UKM pengolahan hasil pertanian

Oleh karena itu, melalui pelatihan ini juga dapat menambah aspek ekonomi masyarakat dan juga dapat dibentuk unit usaha baru di BUMDes "Maju Bersama” desa Kikia Kecamatan Sumalata.

Namun hasil ini juga faktor penentu untuk mendukung prospek ini perlu ditunjang dengan sistem pemasaran, strategi dan komunikasi bisnis yang jitu. Seperti yang dikemukakan oleh Kotler dan Armstrong (2001) bahwa bauran pemasaran yang terdiri dari 4P (product, price, place, promotion) sebagai seperangkat alat pemasaran taktis dan terkontrol yang dipadukan oleh produsen untuk menghasilkan respon yang diinginkan pasar sasaran. Bauran pemasaran diatas memiliki kekuatannya masing-masing yang harus bersinergi satu sama lain. Produk merupakan kombinasi barang dan jasa yang ditawarkan produsen kepada pasar sasaran. Harga merupakan sejumlah uang yang harus dibayar konsumen untuk memperoleh produk. Distribusi meliputi aktivitas produsen agar produk mudah didapatkan konsumen sasarannya. Promosi berarti aktivitas mengkomunikasikan keunggulan produk serta membujuk pelanggan sasaran untuk membeli produk tersebut. 


\section{KESIMPULAN}

Pemberdayaan masyarakat di Desa Kikia bertujuan untuk memperkuat perekonomian dan meningkatkan kesejahteraan masyarakat. Program pengembangan UKM dan BUMDes merupakan salah satu alternative yang dapat dilakukan melalui kegiatan pemberdayaan masyarakat. Pemberian pelatihan dan diklat dalam bentuk penguatan kelembagaan UKM dan BUMDes maupun pelatihan peningkatan ketrampilan bagi UKM di Desa Kikia diharapkan dapat mendorong peningkatan pendapatan masyarakat.

Untuk itu kepada Pemerintah Daerah khususnya Pemerintah Desa Kikia agar dapat menindaklanjuti kegiatan yang telah dilakukan. Kelanjutan program sangat ditentukan oleh partisipasi dari seluruh masyarakat dan pemerintah di Desa Kika Kecamatan Sumalata Kabupaten Gorontalo Utara.

\section{UCAPAN TERIMA KASIH}

Ucapan terima kasih kepada seluruh masyarakat dan Pemerintah Desa Kikia, Pemerintah Kecamatan Sumalata dan Pemerintah Kabupaten Gorontalo Utara yang telah mendukung terlaksananya kegiatan pemberdayaan masyarakat di Desa Kika.

\section{REFERENCES}

De la Lastra, S. F.-P., Martin-Alcazar, F., \& Sanchez-Gardey, G. (2014). Functional Flexibility in Human Resource Management Systems: Conceptualization and Measurement. International Journal of Business Administration, 5(1). https://doi.org/10.5430/ijba.v5n1p1

Feriady, M, Kusmuriyanto (2019). The Initiation Of Joint Village-Owned Enterprises (Bumdes) To Increase The Economy Of Villages In 
Jambu Sub-District Semarang Regency, Indonesian Journal of Devotion and Empowerment. 1(1), 1-4. https://journal.unnes.ac.id/sju /index.php /ijde /issue /download/1606/Kusmuriyanto\%2C\%20Muhammad\%20Feriady

Hadi Purnomo, S. (2018). Business Development Strategy of SMEs to Improve Welfare of Craftsmen. International Journal of Innovation, Management and Technology, 9(2), 95-101. https://doi.org/10. 18178/ijimt.2018.9.2.795

Hanaysha, J. (2016). Testing the Effects of Employee Empowerment, Teamwork, and Employee Training on Employee Productivity in Higher Education Sector Jalal. International Journal of Learning \& Development, $6(1)$ 164-178. https://doi.org/10.5296/ijld.v6i1.9200

Igirisa, I., Isa, R. A., \& Tohopi, R. (2020). Institutional Strengthening Strategy of Cocoa Farmer Group in Increasing Income of Cocoa Farmers in Pohuwato Regency, Gorontalo Province. 29(4), 2892-2898. http://sersc.org/journals /index.php/IJAST/ article/view/23466

Igirisa, I., Rahman, M., Abdussamad, J., Abdusamad, Z., \& Husain, A. K. (2020). Implementation of Development Policy for Livestock Farming Business in Gorontalo Regency, Gorontalo , Indonesia. Sys Rev Pharm 2020-11(12), 138-142. https://doi: 10.31838/ srp.2020.12.23

Jones, P., Beynon, M. J., Pickernell, D., \& Packham, G. (2013). Evaluating the impact of different training methods on SME business performance. Environment and Planning C: Government and Policy, 31(1), 56-81. https://doi.org/10.1068/c12113b

Kartikawati, MDT, Mardiyono, \& Makmur, Mohamad. 2015. Perencanaan Program Peningkatan Pemasaran Hasil Produksi Pertanian/Perkebunan di Kota Batu. Reformasi: Jurnal IImiah IImu Sosial dan IImu Politik; Vol 5, No 1 (2015). 136 - 148; http://dx.doi.org/10.33366//fr.v5i1.71 dapat di akses pada laman: https://jurnal.unitri.ac.id/index.php/reformasi/article/view/71/68

Kurniasih, D., \& Setyoko, P.I., Wijaya, S.S, (2019). Strategy implementation on development of village enterprise in banyumas, jawa tengah. 9(2), 134-143. https://doi.org/10.33701/jiwbp.v 9i2.623 
Kotler, Philip dan Gary Amstrong. 2001. Prinsip-Prinsip Pemasaran Jilid Satu Edisi Kedelapan. Diterjemahkan oleh Damos Sihombing, Jakarta: Erlangga

Moscalu, M., Girardone, C., \& Calabrese, R. (2020). SMEs' growth under financing constraints and banking markets integration in the euro area. Journal of Small Business Management, 58(4), 707746. https://doi.org/10.1080/00472778.2019.1668722

Puspitaningtyas, Z. (2017). Pembudayaan Pengelolaan Keuangan Berbasis Akuntansi Bagi Pelaku Usaha Kecil Menengah. Jurnal Akuntansi, 21(3), 361. https://doi.org/10.24912/ja.v21i3.242

Ramly, A., Wahyuddin, W., Jullimursyida, J., \& Mawardati, M. (2020). Business Analysis Of Village-Owned Enterprises (Bumdes): A Poverty Reduction Strategy (Case Study Kuala Sub-District, Nagan Raya Regency). (May). https://doi.org/10.4108/eai.17-102018.2294161

Razak, M. R. R., \& Sofyan, B. (2020). Role of village-owned enterprises in farming community empowerment. International Journal of Advanced Science and Technology, 29(6 Special Issue), 684-691. https://osf.io/5ycva/download

Rekarti, E., \& Doktoralina, C. M. (2017). Improving Business Performance: A Proposed Model for SMEs. European Research Studies Journal, 20(3), 613-623. https://doi.org/10.35808/ersj/732

Sofyani, H., Atmaja, R., \& Rezki, S. B. (2019). Success Factors of Village-Owned Enterprises (BUMDes) Performance in Indonesia: An Exploratory Study. Journal of Accounting and Investment, 20(2). https://doi.org/10.18196/jai.2002116

Utami, W., \& Nugroho, L. (2019). Going Concern Studies of Government Social Enterprise in Indonesia Going Concern Studies of Government Social Enterprise in Indonesia (Village Government Enterprises Case/Bumdes-Lebak Region, West Java Province-Indonesia). International Journal Entrepreneurship and Management Inquiries, 3(5), 191-206. Retrieved from https://www.researchgate.net/publication/338215781 